\title{
Effect of Y/Mg ion ratio and phase assemble on ionic conductivity of multi-doped zirconia ceramic solid electrolytes
}

\author{
Yonggang Hoo, ${ }^{\mathrm{a}, \mathrm{b}, *}$ Yusheng Shi ${ }^{\mathrm{a}}$ and Wenzhong $\mathrm{Lu} \mathrm{u}^{\mathrm{b}}$ \\ ${ }^{a}$ State Key Laboratory of Materials Processing and Die \& Mould \\ Technology, School of Materials Science and Engineering, Huazhong \\ University of Science and Technology, Wuhan 430074, China \\ ${ }^{b}$ School of Optical and Electronic Information, Huazhong University of \\ Science and Technology, Wuhan 430074, China
}

\begin{abstract}
The phase composition design principle is introduced to obtain balanced properties of ionic conductivity and thermo-tolerant for zirconia solid electrolytes used in solid oxide fuel cells (SOFCs). The zirconia ceramic solid electrolytes are fabricated by two-step free sintering. With increasing $\mathrm{Y} / \mathrm{Mg}$ ionic ratio from 1.78:1 to 1.88:1, the content of monoclinic phase fluctuates little $( \pm 3 \%)$. The ionic conductivity, including the total electrical resistance; grain electrical resistance and grain boundary electrical resistance at $1223 \mathrm{~K}$, are all gradually declining with the increasing of $\mathrm{Y} / \mathrm{Mg}$ ionic ratio. Furthermore, the enrichment of $\mathrm{Mg}$ ion in grain boundary acts as a disincentive to grain boundary ionic conductivity. In addition, the maximum total equivalent conductivity at $1223 \mathrm{~K}$ in this study reaches to $0.143 \mathrm{Scm}^{-1}$ which can compare with that of certain YSZ. It will be beneficial to SOFCs application profited from increasing ionic conductivity of ceramic solid electrolytes.
\end{abstract}

Keywords: phase assemble, zirconia electrolyte, ionic conductivity, SOFCs.

*Correspondending authors. Tel: +86(0)2787558155.

E-mail address: yongganghu@hust.edu.cn (Y.G. Hoo). 


\section{Introduction}

The "first generation" solid oxide fuel cells (YSZ-based) possess potential highperformance [1-3] but high operating temperature of about $1173 \mathrm{~K}$ for using hydrogen fuel. As a clean energy application case, the emission is only water. However, the high grain boundary resistance for oxygen ion transport and weak refractory behavior $[4,5]$ of YSZ-based solid electrolytes were considered as a constraint on their further industrial application. The rare-earth elements doped electrolytes offer potential exceptional performance at lower temperature [6-8], but the high cost of materials results in a continuous supply challenge, and the rough running performance for unstable operation was not well solved yet.

Magnesia doped zirconia ultrathin electrolytes demonstrated good thermal shock resistance [9-10] at high temperature. Accordingly, magnesia and yttria multidoped zirconia ceramics offer the fascinating potential for moderate temperature, lower-cost and high performance ceramic electrolytes if appropriately fabricated. Magnesia and yttria multi-doped zirconia ceramics added with sintering agents such as $\mathrm{Al}_{2} \mathrm{O}_{3}$ and $\mathrm{CaO}$ also offer other benefits such as lower sintering temperature and compatibility two types of conduction. However, the reported performance of $\mathrm{Y}_{2} \mathrm{O}_{3}$ $\mathrm{MgO}$ multi-doped ceramic solid electrolytes is not intriguing and inferior to the performance of YSZ. In recent years, core-shell structured multi-doped ceramic solid electrolytes with attractive conductivity performance have been suggested by our theoretical derivation. If this can be achieved, the topic of potential superiority of the multi-doped ceramic solid electrolytes could be full of interest to researchers. To our best knowledge, there has little attention on it up to now. Nevertheless, the potential benefits of the multi-doped ceramic solid electrolytes can eventually make it possible 
to behave excellent combination properties for SOFCs assuming the use of ideal electrode.

In the present work, the complex oxides of $\mathrm{Y}_{2} \mathrm{O}_{3}-\mathrm{MgO}-\mathrm{Al}_{2} \mathrm{O}_{3}-\mathrm{CaO}$ multi-doped zirconia (named as $\mathrm{Zr}-\mathrm{Y}-\mathrm{Mg}-\mathrm{Al}-\mathrm{Ca}-\mathrm{O}$ in the following) ceramic solid electrolytes were fabricated by a two-step free sintering to investigate the microstructure characteristic and ionic electrical conductivity. With adjusting the $\mathrm{Y} / \mathrm{Mg}$ ion ratio, the high temperature ionic conductivity of sintered ceramics was evaluated by AC impedance. The affect of ions distribution on ionic electrical conductivity was analyzed. Then, the influence of $\mathrm{Y} / \mathrm{Mg}$ ion ratio on the microstructure, phase characteristic was studied and the conduction mechanism was discussed.

\section{Experimental processes}

The raw powder of Zr-Y-Mg-Al-Ca-O was supplied by Sansai Company (Yixing, China). The multi-doped zirconia raw materials were designed as shown in Table 1. The particle size distribution is determined by an SA-CP3 type particle size analyzer (Japan). Fig.1 (a), (b) and (c) show the particle size distribution of multi-doped zirconia powders (Zr-Y-Mg-Al-Ca-O, where $\mathrm{Y} / \mathrm{Mg}=1.78: 1,1.83: 1,1.88: 1)$. As can be seen in Fig. 1, the particle size distributions are all bimodal distribution of $1 \mu \mathrm{m}$ and $4.5 \mu \mathrm{m}$. The process of $\mathrm{Zr}-\mathrm{Y}-\mathrm{Mg}-\mathrm{Al}-\mathrm{Ca}-\mathrm{O}$ specimen preparation includes following four steps (as shown in Fig. 2): (i) milling of powder with binding agent to coating PVA on it; (ii) filtering of powder so as to filter the powder above $10 \mu \mathrm{m}$; (iii) filling the under sieve powder into die to form targeted samples; (iv) sintering of the formed samples at high temperature. Dry pressing technology shows three advantages when compared to other traditional technologies such as injection molding: (i) no special process of binder exclusion; (ii) high density, operation simplification and cost- 

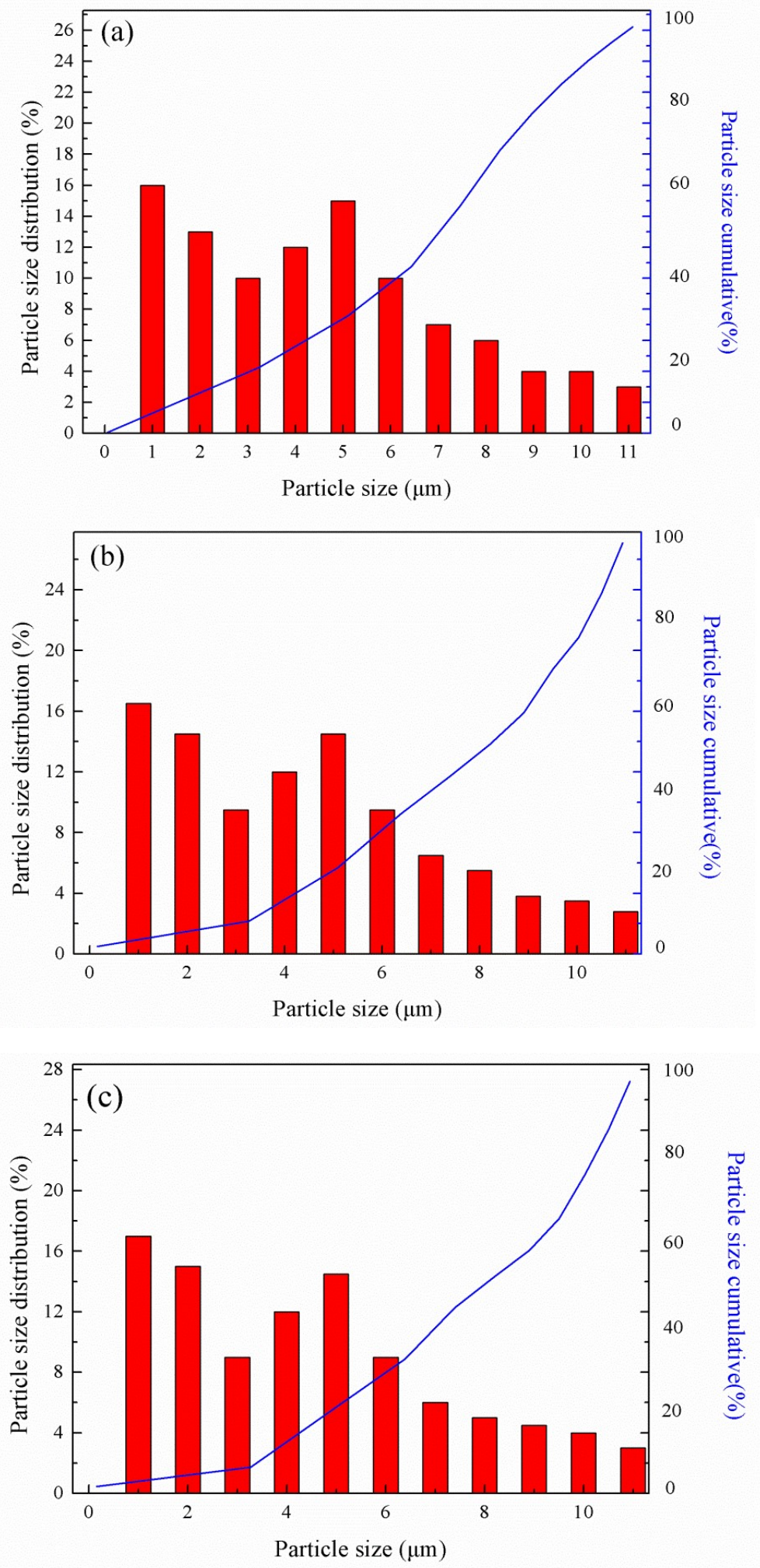

Fig.1 The particle size distributions of Zr-Y-Mg-Al-Ca-O powders (where $\mathrm{Y} / \mathrm{Mg}=1.78: 1,1.83: 1,1.88: 1$, shown in (a), (b) and (c) respectively). 
Table 1 Compositions of Zr-Y-Mg-Al-Ca-O raw materials (/mol\%)

\begin{tabular}{lllllll}
\hline Sample & $\mathrm{ZrO}_{2}$ & $\mathrm{Y}_{2} \mathrm{O}_{3}$ & $\mathrm{MgO}$ & $\mathrm{CaO}$ & $\mathrm{Al}_{2} \mathrm{O}_{3}$ & $\mathrm{Y} / \mathrm{M}$ \\
\hline $\mathrm{S} 1$ & 89.96 & 4.58 & 2.56 & 2 & 1 & $1.78: 1$ \\
$\mathrm{~S} 2$ & 89.96 & 4.62 & 2.52 & 2 & 1 & $1.83: 1$ \\
$\mathrm{~S} 3$ & 89.96 & 4.66 & 2.48 & 2 & 1 & $1.88: 1$ \\
\hline
\end{tabular}

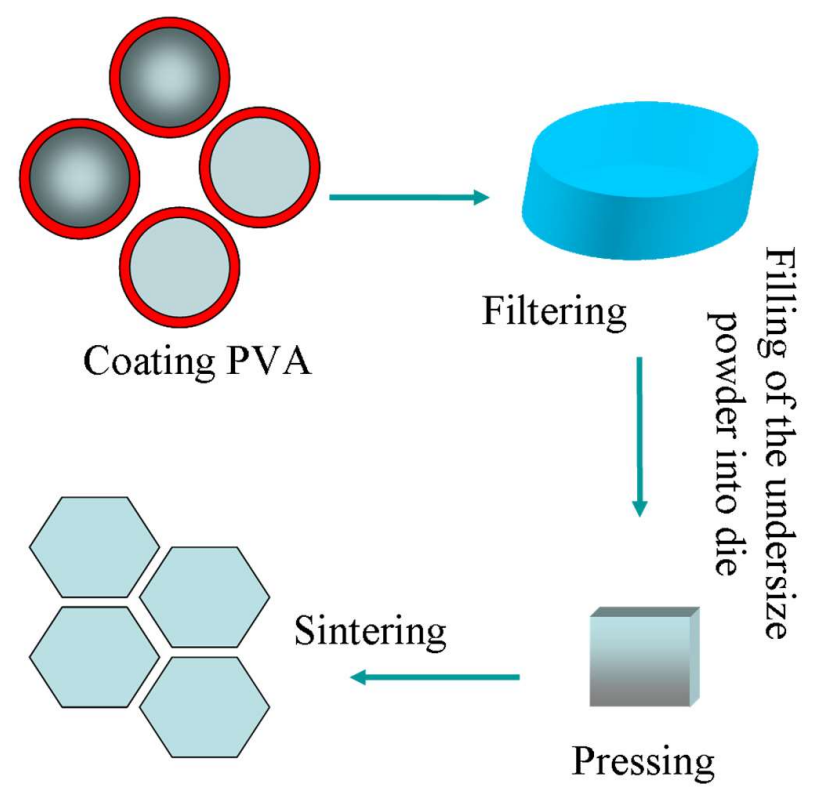

Fig.2 The schematic flow diagram of the preparation of Zr-Y-Mg-Al-Ca-O ceramics.

effective; (iii) adequate distributed powder with no particle further settlement. Firstly, the Zr-Y-Mg-Al-Ca-O powders were milled by rotation ball milling with 10vol\%PVA aqueous suspension (powder-to-ball weight ratio of 5:1, with a rotation speed of $150 \mathrm{rpm}$ for 5h). Then the Zr-Y-Mg-Al-Ca-O powders were dried at $373 \mathrm{~K}$.

Furthermore, the powders were pressed by isostatic forming machine at $80 \mathrm{MPa}$ to obtain the green bodies. Finally, the biscuits were sintered by two-step free sintering $(1873 \mathrm{~K} \times 2 \mathrm{~h}+1423 \mathrm{~K} \times 2 \mathrm{~h})$ in air atmosphere with a $3 \mathrm{~K} / \mathrm{min}$ heat-up rate for following test.

The density of specimen after sintering was calculated by Archimedes principle. The ionic conductivity of specimen coated with Pt $(6 \mathrm{~mm} \times 6 \mathrm{~mm} \times 1 \mathrm{~mm})$ were measured every $100 \mathrm{~K}$ for holding 5 min from $723 \mathrm{~K}$ to $1273 \mathrm{~K}$ by Frequency 
Response Analyzer (Solartron 1260, UK) in the frequency range of $0.01 \mathrm{~Hz}-10 \mathrm{MHz}$. The value of total equivalent conductivity at different temperature is calculated based on fitting criterion. Phase characteristics were presented by X'Pert PRO diffraction (PANalytical B.V., Cu-Ka) at a scan rate of $0.2 \%$ min (parameters: electric voltage $=$ $40 \mathrm{kV}$, electric current $=20 \mathrm{~mA}$, scan range $\left.2 \theta=20-90^{\circ}\right)$. The monoclinic $(\mathrm{m})$ phase content is calculated by the formula (1) (where: tetragonal-t, cubic-c) [11]. The surface microstructure of specimen was observed by scanning electron microscope (Quanta 200, FEI).

$\mathrm{V}_{\mathrm{m}}(\%)=\frac{\mathrm{I}_{\mathrm{m}}(111)+\mathrm{I}_{\mathrm{m}}(11 \overline{1})}{\mathrm{I}_{\mathrm{m}}(111)+\mathrm{I}_{\mathrm{m}}(11 \overline{1})+\mathrm{I}_{\mathrm{t}+\mathrm{c}}(111)} \times 100 \%$

where $\mathrm{V}_{\mathrm{m}}$ is the content of $\mathrm{m}$ phase in sintered partially stabilized zirconia (PSZ)

sample, and $\mathrm{I}_{111 \mathrm{~m}}, \mathrm{I}_{11}{ }^{-} \mathrm{m}, \mathrm{I}_{111 \mathrm{t}, \mathrm{c}}$ is the diffracted intensity of $28.355^{\circ}, 31.624^{\circ}, 30.409^{\circ}$, respectively.

\section{Results and discussion}

\subsection{Elements distribution, microstructure and phase assemblage}

Fig. 3 implicates the partial distribution of $\mathrm{Y}$ and $\mathrm{Mg}$ element in the sintered $\mathrm{S} 1$ sample. The Y ion is clearly visible in the area of grains (shown in Fig. 3c), and it can be seen that the $\mathrm{Mg}$ ion is mostly distributed along the grain boundaries (shown in Fig. 3a, zooming in it for a clear view). Furthermore, the accumulative Mg ion obviously seen in Fig. 3a is because of the forming of Mg-Al spinel. With the aim of studying the influence of doping ion ratio on phase assemblage of $\mathrm{Zr}-\mathrm{Y}-\mathrm{Mg}-\mathrm{Al}-\mathrm{Ca}-\mathrm{O}$ ceramics, $\mathrm{XRD}$ is conducted on the samples with different $\mathrm{Y} / \mathrm{Mg}$ ion rate. The XRD patterns and microstructures are illustrated in Fig. 4. From the results shown in Fig.4d, 


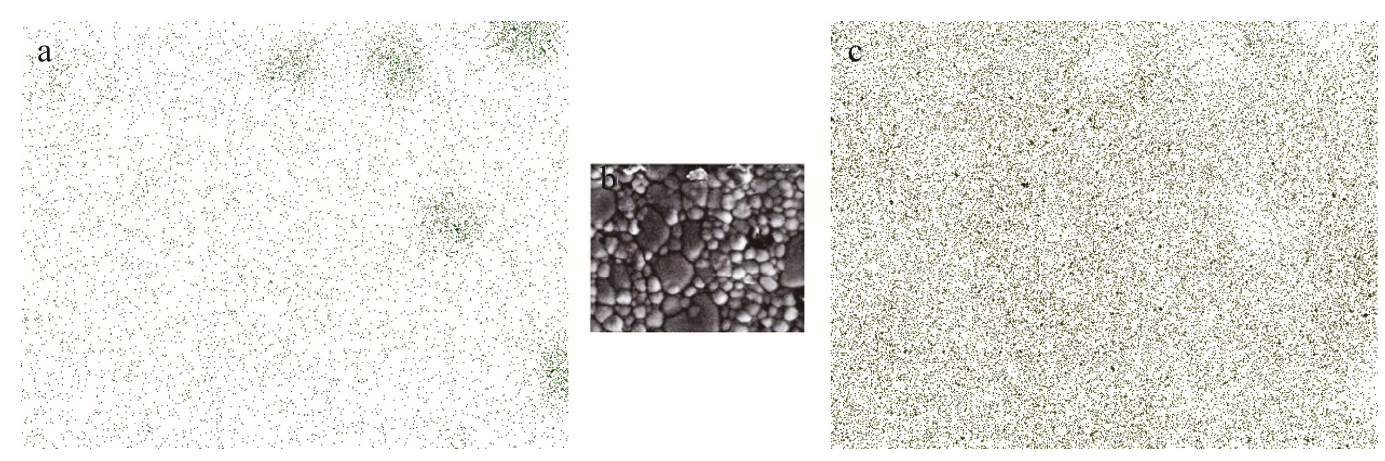

Fig. 3 Partial element distribution maps of $\mathrm{Mg}$ (a) and Y (c) obtained from the sintered SP1 sample according to the microstructure as shown in (b).
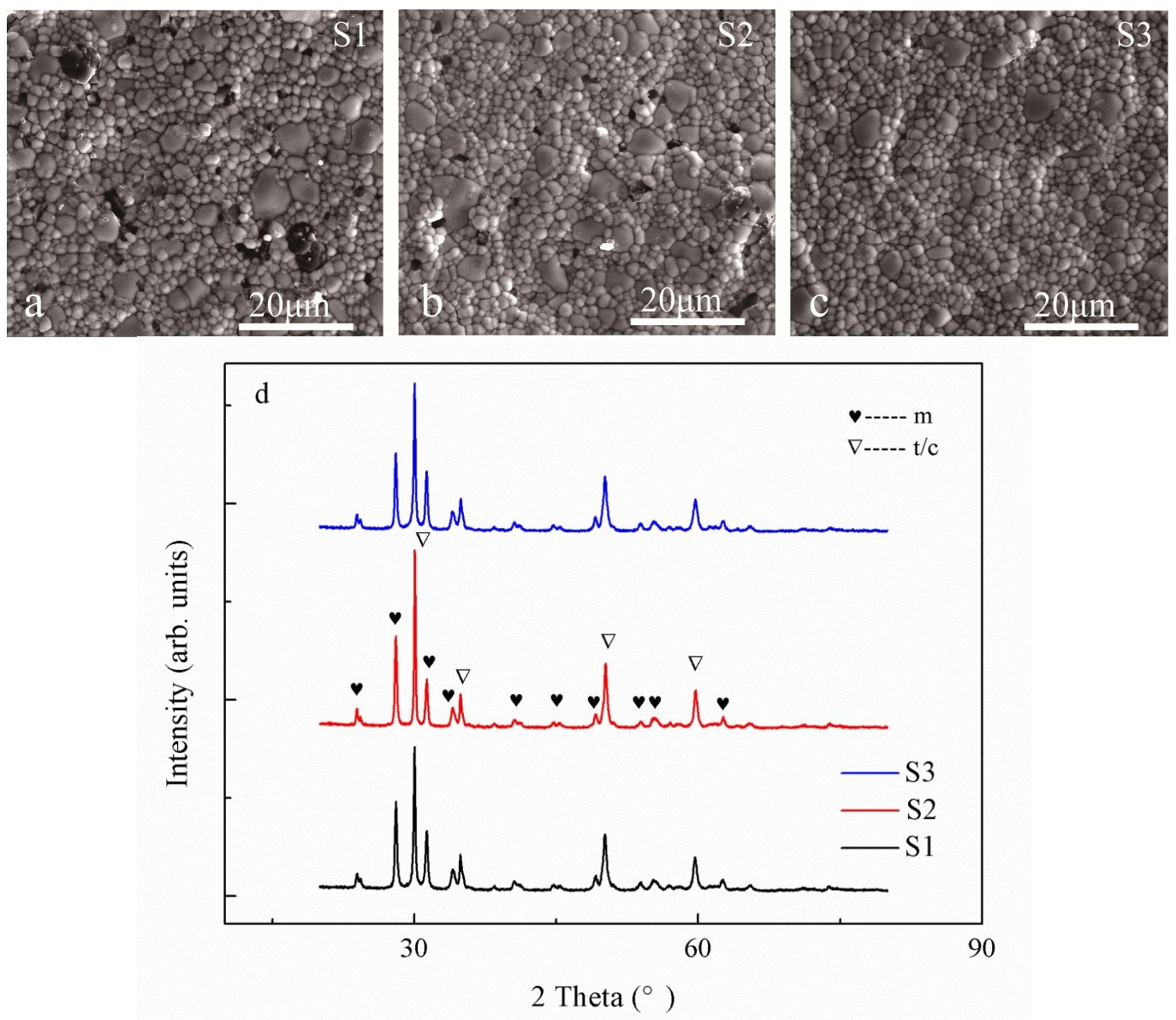

Fig. 4 The heterogeneous microstructures with coarse grains (SEM) and phase composition (XRD) obtained from the sintered PSZ samples. 
the fractions of $m$ phase calculated by equation (1) in the three samples are mainly similar to each other. In other words, with increasing $\mathrm{Y} / \mathrm{Mg}$ ionic ratio from 1.78:1 to $1.88: 1$, the content of $\mathrm{m}$ phase fluctuates little.

In addition, as the results shown in SEM pictures, the number of coarse grains is varied with the additive content. With the increasing of $\mathrm{Y}$ ion, the number of bigger coarse grains declines gradually and the number of mid-coarse grains increases. This could be associated with the block effect of spinel [2] owing to the increasing of $\mathrm{Mg}$ ion content; the number of black spinels is conspicuously increasing which plays a role in energy concentration to induce the coarsening of grains. According to our previous studying [12], the coarsening grains were in association with a heat treat process without considering the affect of the component. In this study, the same sintering process has been conducted on all samples but with a different ratio of constituents. In summary, it shows that there has a more important influence of $\mathrm{Y} / \mathrm{Mg}$ ion ratio on the grain size distribution rather than the content of $\mathrm{m}$ phase if used the same sintering process.

\subsection{Equivalent conductivity varied with $\mathrm{Y} / \mathrm{Mg}$ ion ratio}

The equivalent conductivities of the sintered ceramics samples were studied by Frequency Response Analyzer at a temperature range of $723 \mathrm{~K}$ to $1273 \mathrm{~K}$. The typical impedance spectra comprise a high-frequency impedance arc and a low-frequency impedance arc related to the grain and grain boundary resistor-capacitor (RC) effect, respectively (shown in Fig.5). From the impedance spectra shown in Fig.5, it can be seen that with the increasing of $\mathrm{Y} / \mathrm{Mg}$ ion ratio, the total electrical resistance is gradually declining at $1223 \mathrm{~K}$, and both the grain electrical resistance and grain 

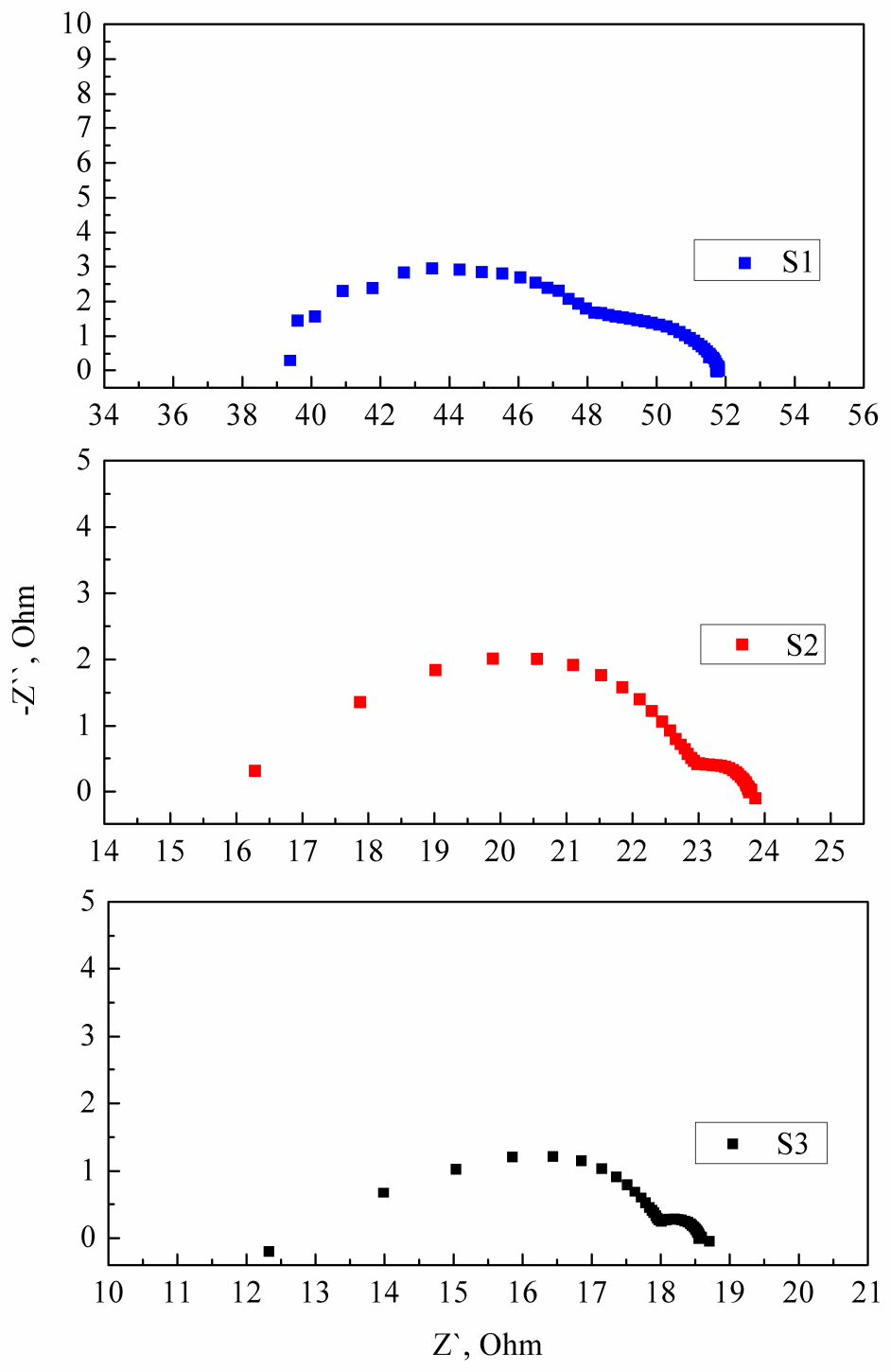

Fig.5 Impedance spectra of S1, S2 and S3 samples varied with the Y/Mg ion rate tested at $1223 \mathrm{~K}$.

boundary electrical resistance are in conformity with that trend. The declining rate of grain electrical resistance is diminishing. But with the increasing of $\mathrm{Y} / \mathrm{Mg}$ ion ratio, the grain boundary electrical resistance has a proportionate drop. Based on the element distribution results shown in Fig. 3, the decreasing of grain boundary electrical resistance is related to the decreasing of $\mathrm{Mg}$ ion content that along grain boundary, i.e. the enrichment of $\mathrm{Mg}$ ion in grain boundary acts as a disincentive to 


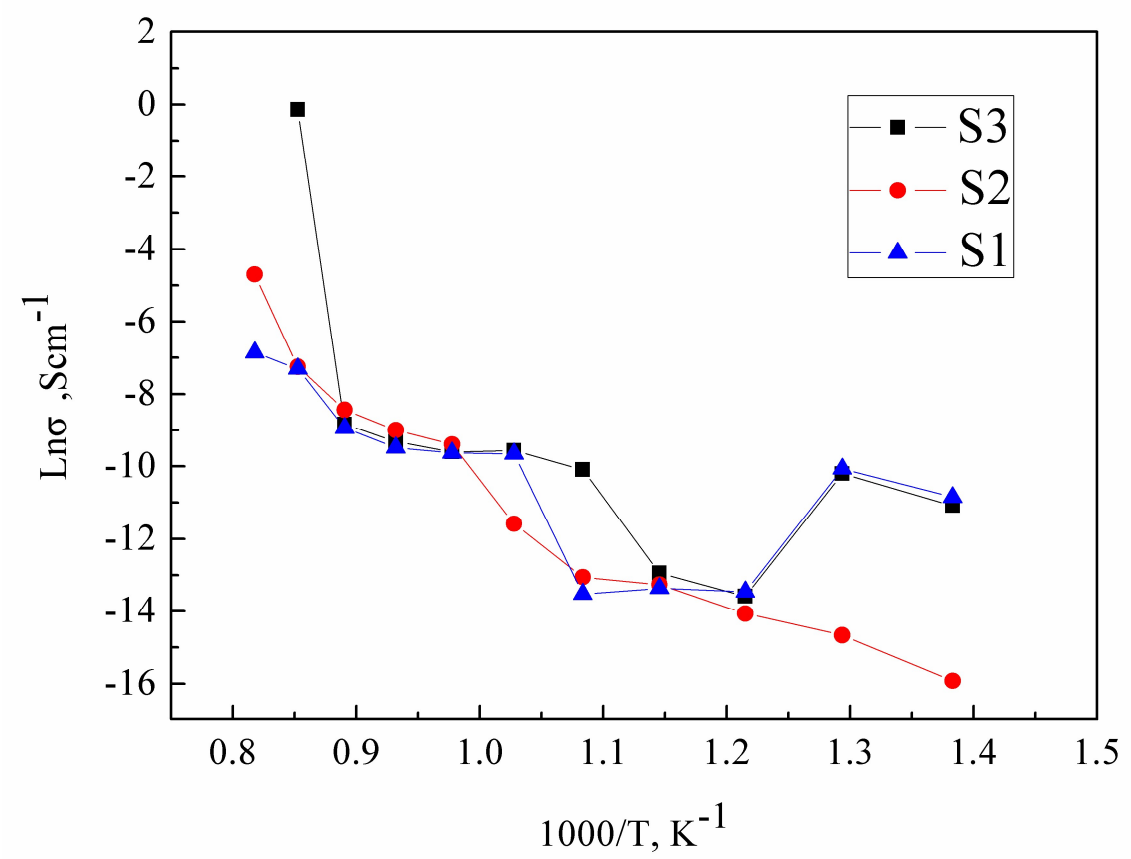

Fig.6 Total equivalent conductivity of S1, S2 and S3 samples varied with temperature $(723-1273 K)$.

grain boundary conductivity. Furthermore, the increasing of grain conductivity affected by the increasing of $\mathrm{Y}$ ion content is weakened slowly due to the saturated substitution of $\mathrm{Y}^{3+}$ for $\mathrm{Zr}^{2+}$ lattice site.

\subsection{Discussions}

From the results shown in Fig. 6, the maximum total equivalent conductivity obtained in $\mathrm{S} 3$ ceramics is $0.143 \mathrm{Scm}^{-1}$ at $1223 \mathrm{~K}$, which is better than that of $\mathrm{Sm}_{2}$ ${ }_{x} \mathrm{La}_{x} \mathrm{Zr}_{2} \mathrm{O}_{7}$ [13] or Sc-Yb-Zr-Ca-O measured at the same temperature [14], even than that of 8YSZ reported in literature (max: $0.129 \mathrm{~S} / \mathrm{cm})[15]$ at the same temperature; and can compare with that of YSZ reported in [16].

As the results shown in Fig.6, it reveals that the total equivalent conductivity of $\mathrm{S} 3$ at $1223 \mathrm{~K}$ is the highest. However, at the lower temperature range, a random arrangement of the total equivalent conductivity of S1, S2 and S3 is found which may 
be related to the influencing factor of grain boundary electrical resistance and grain electrical resistance. From the results shown in Fig. 5 and Fig. 6, it can be concluded that a more extraordinary influence of grain boundary conductivity on the total conductivity (as the blocking effect) than that of grain conductivity dominates the development of total conductivity at high temperature. The model of ionic transport route is changed from grain conduction to multi-channel grain boundary conduction, named as preferred transport route (PTR). According to the typical microstructure, the number and distribution of coarse grains could play a key role in grain impedance. The disadvantageous affect of more coarse grains on conductivity at high temperature is involved in the increasing of grain electrical resistance due to the coarsening. The effect of $\mathrm{Mg}$ ion content on the grain boundary conductivity reveals that the highpure/clean grain boundary is beneficial to total equivalent conductivity at high temperature. Although the grain boundary of $\mathrm{Zr}-\mathrm{Y}-\mathrm{Mg}-\mathrm{Al}-\mathrm{Ca}-\mathrm{O}$ ceramics in this study is not high-pure, as a second-phase among grains, it will be transforming to a good conductor with the increasing of temperature called partially clogged grain boundary good conductor (such as a core-shell structured grain).

\section{Conclusions}

The elements distribution, microstructure, phase assemblage, and total equivalent conductivity of prepared $\mathrm{Zr}-\mathrm{Y}-\mathrm{Mg}-\mathrm{Al}-\mathrm{Ca}-\mathrm{O}$ ceramics were investigated. The conduction mechanism was discussed. The main conclusions are summarized in the following:

(1) The prepared multi-doped zirconia ceramic solid electrolytes have a polymorph structure composed of $\mathrm{m}, \mathrm{t}$ and $\mathrm{c}$ phase. The maximum total equivalent conductivity 
of it reaches to $0.143 \mathrm{Scm}^{-1}$ at $1223 \mathrm{~K}$ which is better than that of $\mathrm{Sm}_{2-\mathrm{x}} \mathrm{La}_{\mathrm{x}} \mathrm{Zr}_{2} \mathrm{O}_{7}$ and Sc-Yb-Zr-Ca-O, even better than that of $8 \mathrm{YSZ}$ at the same temperature.

(2) With the increasing of Y/Mg ion ratio, the total equivalent conductivity sequence of prepared samples is $\mathrm{S} 3>\mathrm{S} 2>\mathrm{S} 1$ at high temperature range. A more extraordinary influence of grain boundary conductivity dominates the development of total conductivity at high temperature than that of grain conductivity. A second-phase good conductor among grains will be beneficial to the total equivalent conductivity even if it is not pure grain boundary.

Although some significant progress has been made, further improvement should benefit greatly by exploring other possible related factors.

\section{Acknowledgments}

This work was partially supported by the National Key Foundation Research plan of China (61362). Thanks are kindly expressed to Prof. Jianzhong Xiao for his support to finish the experiments. The authors are grateful for the Analysis and Testing Center of Huazhong University of Science and Technology for XRD and SEM tests, as well as Ningbo Institute of Industrial Technology for ionic conductivity tests. Thank Dr. Qingqing Yang and Dr. Huatang Tan for particle size testing. We also thank Professor Monica Ferraris and the anonymous referees` useful comments for improving the draft.

\section{References}

[1] D. Maeland, C. Suciu, I. Waernhus, A.C. Hoffmann. J. Eur. Ceram. Soc. 29 (2009) 2537-2547.

[2] S. Tekeli. Mater. Des. 28 (2007) 713-716.

[3] T. Jardiel, B. Levenfeld, R. Jimenez, A. Varez. Ceram. Int. 35 (2009) 2329-2335. 
[4] T. Zhang, Z. Zeng, H. Huang, P. Hing, J. Kinler. Mater. Lett. 57 (2002) 124-129.

[5] F.L. Lowrie, R.D. Rawlings. J. Eur. Ceram. Soc. 20 (2000) 751-760.

[6] J. Patakangas, Y. Ma, Y. Jing, P. Lund. J. Power Sources 263 (2014) 315-331.

[7] J. Yang, B.F. Ji, J.Y. Si, Q.Z. Zhang, Q.Y. Yin, J.S. Xie, C.A. Tian. Int. J. Hydrogen Energy 41 (2016) 15979-15984.

[8] K. Sugihara, M. Asamoto, Y. Itagaki, T. Takemasa, S. Yamaguchi, Y. Sadaoka, H. Yahiro. Solid State Ionics 262 (2014) 433-437.

[9] T. Sato, M. Ishltsuka, M. Shimada. Mater. Des. 9 (1998) 204-212.

[10] M.V. Swain, R.C. Garvie, R.H.J. Hannink. J. Am. Ceram. Soc. 66 (1983) 358-362.

[11] H. Tsubakino, K. Sonoda, R. Nozato. J. Mater. Sci. Lett. 12 (1993) 196-198.

[12] Y.G.Hu, J.Z. Xiao, F. Xia, H.B. Zhang. J. Wuhan Uni. Tech.-Mater. Sci. Ed. 28 (2013) 483486.

[13] Z.G. Liu, J.H. Ouyang, Y. Zhou, J. Xiang, X.M. Liu, Mater. Des. 32 (2011) 4201-4206.

[14] Z.G. Lv, R.S. Guo, P. Yao, F.Y. Dai, Mater. Des. 28 (2007) 1399-1403.

[15] C.S. Hellberg, N. Bernstein, S.C. Erwin. APS Meeting. (2016).

[16] I.R. Gibson, G.P. Dransfield, J.T.S. Irvine. J. Mater. Sci. 33(1998)4297-4305. 